\title{
Prognostication of Traumatic Brain Injury using International Mission for Prognosis and Analysis of Clinical Trials in Traumatic Brain Injury score in Nepalese Cohort
}

\author{
Binit Kumar Jha $M S^{1}$ iD, Prabhat Jha $M S^{2}$ iD, Bikesh Khambu $M C h^{3}$ iD, Rajendra Shrestha $M C h^{4}$ iD, Rajiv Jha \\ $\mathrm{MCh}^{5}$ iD, Prakash Bista $\mathrm{MCh}^{6}$ iD \\ ${ }_{1,2,3,4,5,6}$ Department of Neurosurgery, National Neurological Referral Center, National Academy of Medical Sciences, \\ Kathmandu, Nepal
}

Date of submission: $1^{\text {st }}$ August 2021

Date of acceptance: $17^{\text {th }}$ November 2021

Date of publication: $1^{\text {st }}$ December 2021

\section{Abstract}

Introduction: Traumatic brain injury is a disease of major global importance. Prognostic models are useful for making decisions in clinical practice. The aim of this study was to assess the accuracy of International Mission for Prognosis and Analysis of Clinical Trials in TBI (IMPACT) score in predicting outcome in moderate to severe TBI at 6 months.

Materials and Methods: All patients admitted to the National Trauma Center, National Academy of Medical Sciences with moderate to severe traumatic brain injury from February 2020 to February 2021 were included in the study. IMPACT scores (core/ extended core/ lab) were recorded separately at admission. Outcome was measured with the Glasgow Outcome Scale (GOS) at the time of discharge and at six months. Correlation between observed and predicted outcomes was evaluated by Pearson's correlation coefficient (r). Sensitivity and specificity were plotted in the receiver-operating characteristic (ROC) curve, and the area under the curve (AUC) was calculated to determine the discrimination ability of this prognostic model.

Results: A total of 112 patients were enrolled in the study. Eighty (71.4\%) patients had moderate and $32(28.57 \%)$ had severe TBI. The median age was 33 years with male preponderance (M: $F=4: 1)$. Thirty-three $(29.5 \%)$ patients died within 6 months of TBI, and 38 (33.9\%) patients had an unfavorable outcome. Pearson correlation coefficient showed good correlation between observed and predicted outcomes. Hosmer-Lemeshow test showed good model fit for IMPACT core, IMPACT extended and IMPACT lab in diagnosing mortality and unfavorable outcome in six months $(\mathrm{p}>0.05)$. The ROC curve indicated that all 3 models could accurately discriminate between favorable and unfavorable outcomes, as well as between survival and mortality (unfavorable outcome $\mathrm{AUC}=0.905,0.940,0.955$; mortality $\mathrm{AUC}=0.875,0.914,0.917$ respectively) in our patients.

Conclusion: The IMPACT score is a good prognostic model to predict 6-month outcomes in moderate to severe TBI at admission in Nepalese patient population. Among the three IMPACT models, IMPACT lab has the greatest discriminating ability.

Key words: IMPACT score, Nepalese, Prognosis, Traumatic Brain injury

Access this article online

Website: https://www.nepjol.info/index.php/NJN

DOI: https://doi.org/10.3126/njn.v18i4.38739

HOW TO CITE

Jha BK, Jha P, Khambu B, Shrestha R, Jha R, Bista P. Prognostication of Traumatic Brain Injury using International Mission for Prognosis and Analysis of Clinical Trials in Traumatic Brain Injury score in Nepalese Cohort. NJNS. 2021;18(4):16-32.

Address for correspondence:

Dr Binit Kumar Jha,

National Neurological Referral Center,

National Academy of Medical Sciences,

Kathmandu, Nepal

E-mail: binitjha.95@gmail.com

Phone: +977-9851208714

\section{Introduction}

Traumatic brain injury (TBI) is one of the leading causes of morbidity and mortality in the world ${ }^{1}$, and no major improvements in prognosis has been noted in recent decades. ${ }^{2}$ It is difficult to standardize for differences in quality of care provided by the different institutions. Benchmarking, by comparing the predicted and observed

Copyright (C) 2021 Nepalese Society of Neurosurgeons (NESON)

ISSN: 1813-1948 (Print), 1813-1956 (Online) 
outcome, is an important tool for trauma health care quality evaluation. Improvements in quality of care and outcome can be achieved by using newly developed robust prediction models. ${ }^{3}$

Patients with TBI differ substantially in terms of prognosis from other critically ill patients, and several prognostic models specifically aimed for TBI have been developed. ${ }^{4}$ The most robust and clinical applicable is the IMPACT (International Mission for Prognosis and Analysis of Clinical Trials) model, which uses admission characteristics to predict risk of 6-month outcome. ${ }^{5}$

However, the IMPACT model is fairly new (introduced in 2008) and not as well established in centers around the world as the "traditional" intensive care unit (ICU) scoring systems, such as the APACHE II (Acute Physiology and Chronic Health Evaluation II). In contrast to the IMPACT, the APACHE II does not consider admission characteristics, but instead uses 12 physiological variables measured in the first 24 hour in the ICU. ${ }^{6}$

Steyerberg et al. aimed to develop prognostic models based on admission characteristics, which would allow application of the model before in-hospital therapeutic interventions. ${ }^{7}$ They used several large patient series for model development as available in the International Mission for Prognosis and Analysis of Clinical Trials in TBI (IMPACT) project. The IMPACT database includes patients with moderate and severe TBI $(\mathrm{GCS} \leq 12)$ from eight randomized controlled trials and three observational studies conducted between 1984 and 1997. The endpoint for the prognostic analyses was the 6-month GOS, which is an ordered outcome with five categories: 1, dead; 2, vegetative state; 3 , severe disability; 4, moderate disability; and 5 , good recovery. ${ }^{8}$

In patients whose 6 months assessment was not available 3 months GOS was used ( $n=1,611,19 \%$ of the patients). A total of 8,509 patients were selected. The results were externally validated using patients enrolled in the Medical Research Council Corticosteroid Randomization after Significant Head Injury (MRC CRASH) trial who were recruited between 1999 and 2004. ${ }^{9}$ The validation focused on prediction of mortality (GOS 1) versus survival (GOS 2-5) and of unfavorable (GOS 1-3) versus favorable outcome (GOS 4-5).

The authors initially examined a set of 26 potential predictors. These included demographics (age, sex, race, education), indicators of clinical severity (cause of injury, GCS components, pupillary reactivity), secondary insults (hypoxia, hypotension, hypothermia), blood pressure (systolic, diastolic), various CT characteristics and various biochemical variables. ${ }^{10}$

Three prognostic models were defined (Table 1)

Proportional odds logistic regression analysis was performed with the 6-month GOS as an ordinal outcome. Final prognostic models were developed with logistic regression analysis for dichotomized versions for the GOS: mortality (versus survival) and unfavorable outcome (versus favorable outcome). ${ }^{10}$ All analyses were stratified by study. For the continuous predictors like age, glucose, and Hemoglobin $(\mathrm{Hb})$, a linear relationship with outcome was found to be a good approximation after assessment of nonlinearity using restricted cubic splines. ${ }^{10}$

We believe IMPACT score could serve as a useful tool for predicting outcomes in patients with traumatic brain injury in our setup.

We conducted this study with general objective of prognosticating patients with traumatic brain injury in Nepalese population using IMPACT model. The specific objectives were to assess baseline characteristics of moderate and severe traumatic brain injury patients at admission, assess Glasgow Outcome Score (GOS) of moderate and severe traumatic brain injury patients at six months and correlate the impact core, extended and lab scores with GOS at one and six months

\section{Materials and Methods}

This is an analytical cohort study conducted at National Trauma Center, National Academy of Medical Sciences from February 2020 to February 2021.

Sample size was calculated by the formula purposed by Riley et al.

$$
n=\left(\frac{1.96}{\delta}\right)^{2} \hat{\phi}(1-\hat{\phi})
$$

Where, n: sample size, $\delta$ : absolute margin of error, Ǿ: anticipated outcome proportion. It is generally recommended aiming for a margin of $\operatorname{error}(\delta) \leq 0.05$. Then assuming an anticipated outcome proportion (incidence) of 0.1 in the study population as per Dewan et al., the required sample size was 112 .

Patients with moderate and severe traumatic brain injury defined as GCS $\leq 13$ were included in the study. Patients with mild head injury and younger than 14 years of age were excluded. Five cases were lost to follow up for which additional cases were included.

Study variables analysed were age, sex, IMPACT score, GOS level. Admission characteristics were assessed by an emergency department physician/neurosurgery resident. Patient head CT scans were evaluated by a radiologist/neurosurgeon. Treatment standards in the hospital were followed based on the Brain Trauma Foundation guidelines. Glasgow Outcome Scale measured at 6 months. Neurological outcome determined based on outpatient clinic follow-ups by a neurosurgeon at 3 and 6 months from injury according to the GOS and dichotomized to

- Unfavorable (GOS 1-3: death, vegetative state, or severe disability) 


\section{Jha et al}

- Favorable (GOS 4-5: moderate disability and good recovery) outcome

Collected data was analyzed with the SPSS version 21 Microsoft windows program (2018). Descriptive statistics were expressed as means, median and percentages and visualized in tables, graphs and charts whenever applicable. For the inferential statistics, the following tests were used.

- Sensitivity and specificity were calculated for the diagnostic accuracy of IMPACT score and plotted in the ROC, and the AUC was calculated to determine the discrimination ability of the score.

- Calibration between observed and predicted outcomes was done with Hosmer-Lemeshow goodness-of-fit.

- Pearson's correlation coefficient was used to correlate observed and predicted outcomes.

- $\quad p$ value $<0.05$ was considered statistically significant.

Ethical clearance was obtained from the institutional review board, NAMS, Bir Hospital.

\section{Results}

A total of 112 patients were included in the study. Eighty-one (71.9\%) patients had moderate and 31 (28.1\%) had severe TBI. The age range was 17-76 years (median 38 years). Forty-five ( $40 \%)$ the patients belonged to the age group 31-40 years and $30(27 \%)$ of patients belonged to age group 20-30 years.

Eighty-three patients were males and 29 females with a male to female ratio of $2.86: 1$. The most common mode of TBI in our study was fall from height $50(45 \%)$ followed by RTA 43(38\%) followed by physical assault 16 (14\%). Eighty $(71.4 \%)$ patients were managed conservatively whereas 32 (28.5\%) underwent surgery. Out of 32 patients who underwent surgery, $23(71.9 \%)$ were moderate and 9 (28.1\%) were severe.

The baseline characteristics for impact core, extended and lab are presented in Table 2

Outcome was dichotomized into favorable and unfavorable based on the Glasgow Outcome Score. Eighty-eight $(78.6 \%)$ patients had favorable outcome whereas $24(21.4 \%)$ had unfavorable outcome at the time of discharge. At six months 92 (82.1\%) patients had favorable outcome and 20 (17.9\%) had unfavorable outcome. (Table 3)

As for survival and mortality at discharge, 98 (87.5 $\%)$ patients survived and $14(12.25 \%)$ patients died. Out of 20 patients with unfavorable outcomes at discharge, 6 improved to favorable GOS. The remaining 14 patients died. There were no patients in persistent vegetative state.

\section{Correlation between IMPACT Score and GOS}

As shown in table 4, there was a strong correlation between predicted IMPACT core score and GOS at 6 months for mortality and unfavorable outcome with Pearson's correlation coefficient ( $r$ ) of $>0.9$. Similarly, there was also good linear correlation between the IMPACT extended core and IMPACT lab predicted outcomes with GOS in 6 months in terms of mortality and unfavorable outcome. The observed values and those predicted by all these models of IMPACT score has a strong statistically significant correlation with $\mathrm{p}$ value of $<0.001$.

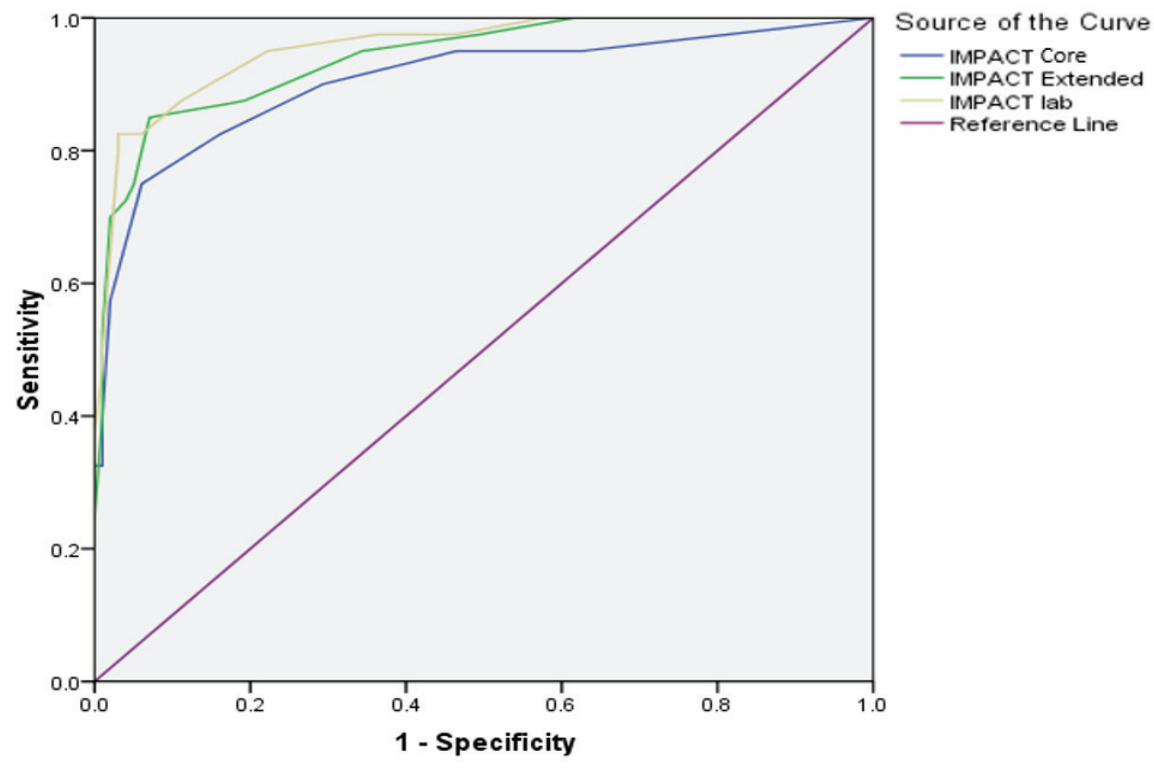

Figure 1: Receiver operating characteristic (ROC) curve for unfavorable outcome in 6 months. 
Prognostication of TBI using IMPACT score

\begin{tabular}{|c|c|c|}
\hline Impact Core & Impact Extended & Impact Lab \\
\hline $\begin{array}{l}\text { - } \quad \text { Age } \\
\text { - } \quad \text { Motor score } \\
\text { - } \quad \text { Pupillary light reactivity } \\
\text { Maximum score: } 15\end{array}$ & $\begin{array}{l}\text { - CT (epidural hematoma, traumatic } \\
\text { subarachnoid hemorrhage, and } \\
\text { Marshall CT classification) } \\
\text { - Secondary insult (hypoxia and } \\
\text { hypotension) } \\
\text { Maximum score: } 22\end{array}$ & $\begin{array}{l}-\quad \text { Glucose } \\
\text { - } \quad \text { Hemoglobin concentrations } \\
\text { Maximum score: } 29\end{array}$ \\
\hline
\end{tabular}

Table 1: Three prognostic models

\begin{tabular}{|c|c|c|}
\hline Model & Admission characteristics & Value \\
\hline \multirow{10}{*}{ IMPACT Core } & Age, median (IQR) & $33(26-50)$ \\
\hline & Motor score, n (\%) & $112(100)$ \\
\hline & Obeys & $44(39.3 \%)$ \\
\hline & Localizes & $52(46.4 \%)$ \\
\hline & Normal flexion & $10(8.9 \%)$ \\
\hline & Abnormal flexion & $3(2.6 \%)$ \\
\hline & None/ extension & $3(4.3)$ \\
\hline & Pupils, n (\%) & $112(100 \%)$ \\
\hline & Both reaction & $90(80.3 \%)$ \\
\hline & One reaction & $15(13.3 \%)$ \\
\hline \multirow{10}{*}{ IMPACT Extended Core } & No reaction & $7(6.25 \%)$ \\
\hline & Hypoxia, n (\%) & $31(22.3)$ \\
\hline & Hypotension, n (\%) & $13(9.4)$ \\
\hline & CT classification, $\mathrm{n}(\%)$ & $112(100)$ \\
\hline & II & $15(13.3 \%)$ \\
\hline & III & $30(26.7 \%)$ \\
\hline & IV & $16(14.3 \%)$ \\
\hline & $\mathrm{V}$ & $51(45.5 \%)$ \\
\hline & Traumatic SAH on CT, n (\%) & $52(46.4 \%)$ \\
\hline & Epidural hematoma on CT, $\mathrm{n}(\%)$ & $48(42.9 \%)$ \\
\hline \multirow{2}{*}{ IMPACT Lab } & Glucose, median (IQR), mg/dl & $122(90-160)$ \\
\hline & Hemoglobin, median (IQR), g/dl & $13.8(11-14)$ \\
\hline
\end{tabular}

Table 2: Patient characteristics on admission by the IMPACT score

\section{Predicted outcome (6 months)}

\section{Percentage $(\%)$}

\section{Unfavorable Outcome}

\begin{tabular}{l|l}
\hline IMPACT core & 20.00 \\
\hline IMPACT extended core & 21.00 \\
\hline IMPACT lab & 23.00 \\
\hline Mortality & 15.00 \\
\hline IMPACT core & 17.00 \\
\hline IMPACT extended core & 14.00 \\
\hline IMPACT lab & \\
\hline
\end{tabular}

Table 3: Predicted outcome by IMPACT score in 6 months. 


\begin{tabular}{l|c|c|c}
\hline \multicolumn{1}{|c|}{ Score } & $\begin{array}{c}\text { Unfavorable outcome } \\
\text { (6months) }\end{array}$ & Mortality (6months) & P-value \\
\hline $\begin{array}{l}\text { IMPACT core } \\
\text { Pearson's Correlation (r) }\end{array}$ & 0.932 & 0.935 & $<0.001$ \\
\hline $\begin{array}{l}\text { IMPACT extended } \\
\text { Pearson Correlation (r) }\end{array}$ & 0.927 & 0.939 & $<0.001$ \\
\hline IMPACT lab & 0.935 & 0.946 & $<0.001$ \\
\hline Pearson Correlation (r) & & & \\
\hline
\end{tabular}

Table 4: Correlation between IMPACT score and GOS

\begin{tabular}{|c|c|c|c|c|c|c|c|}
\hline \multirow[t]{2}{*}{ Study } & \multicolumn{3}{|c|}{ Mortality } & \multicolumn{2}{|c|}{ Unfavorable Outcome } & \multicolumn{2}{|r|}{ Conclusion } \\
\hline & $\begin{array}{l}\text { IMPACT } \\
\text { core }\end{array}$ & $\begin{array}{c}\text { IMPACT } \\
\text { extended core }\end{array}$ & $\begin{array}{l}\text { IMPACT } \\
\quad \text { lab }\end{array}$ & $\begin{array}{l}\text { IMPACT } \\
\text { core }\end{array}$ & $\begin{array}{l}\text { IMPACT } \\
\text { extended } \\
\text { core }\end{array}$ & $\begin{array}{l}\text { IMPACT } \\
\quad \text { lab }\end{array}$ & \\
\hline $\begin{array}{l}\text { Lingsma et al. } \\
2013\end{array}$ & 0.85 & 0.88 & 0.90 & 0.82 & 0.85 & 0.87 & $\begin{array}{l}\text { Good discrimination in } \\
\text { predicting outcomes }\end{array}$ \\
\hline $\begin{array}{l}\text { Raj et al. } \\
2014\end{array}$ & 0.81 & 0.71 & 0.82 & 0.81 & 0.82 & 0.82 & $\begin{array}{l}\text { Good discrimination in } \\
\text { predicting outcomes }\end{array}$ \\
\hline $\begin{array}{l}\text { Egea-Guerrero } \\
\text { et al. } 2018\end{array}$ & 0.843 & 0.876 & 0.90 & 0.828 & 0.836 & 0.843 & $\begin{array}{l}\text { Good discrimination in } \\
\text { predicting outcomes }\end{array}$ \\
\hline Present study & 0.935 & 0.939 & 0.946 & 0.932 & 0.927 & 0.935 & $\begin{array}{l}\text { Good discrimination in } \\
\text { predicting outcomes }\end{array}$ \\
\hline
\end{tabular}

Table 5: Comparison of studies in patients with moderate to severe TBI showing discrimination ability of the score

\section{Discussion}

Traumatic brain injury is a leading cause of death and disability. ${ }^{1}$ Though GCS and GOS provided accurate predictions of prognosis after 24 hours of injury, it was difficult to make accurate predictions at admission. ${ }^{10}$

Decision making in taking care of critically ill and often unstable patients is aided by good prognostic models. ${ }^{10}$ This helps to make decision about the rationale use of the resources as well as informing the family regarding the prognosis at the earliest. Therefore, prognostic model like IMPACT score are extremely useful in this regard..$^{4,10}$ However, this should be regarded as complementary but not as the replacement of clinical judgment.

The IMPACT model was developed as a tool to estimate the absolute risk of unfavorable neurologic outcome and mortality in 6 months in patients with moderate to severe TBI. ${ }^{4,10}$ In this prospective validation study from our center, all iterations of the IMPACT model demonstrated good prediction of both 6-month unfavorable neurologic outcome and mortality. 4,10

In our study, among 112 patients, $80.6 \%$ were males showing male preponderance which was similar in study done by Egea-Guerrero et al., ${ }^{11}$ Wong et al. and Kamal et al. ${ }^{15}$ This emphasizes that the incidence of moderate to severe TBI is more in male population.
The minimum age of the patient enrolled was 18 years. The maximum age of the patients was 81 years with median age of 33 years. This result is consistent with the study done by Egea-Guerrero et al. ${ }^{11}$ which showed median age of 41 years. Panczykowski et al. ${ }^{12}$ and Olivecrona et al. ${ }^{13}$ did their study on adult patients with severe TBI who had mean ages of 37.8 and 35.5 years respectively. On the other hand, Lingmsa et al. ${ }^{14}$ had slightly older median age (48 years) studied in moderate to severe TBI. In our study, most of the patients belonged to the age group 20-29 years $(33.1 \%)$ which was slightly younger than the study done by Kamal et al. ${ }^{15}$ (age group 30-41).

As per the etiology of TBI, the most common mode of injury in our study was fall from height $(46.8 \%)$ followed by RTA (42.8\%). However, in India, the most common cause of moderate and severe TBIs is RTA followed by falls. In developed countries, with increasing life expectancy, fall from height has emerged as the leading cause of head injury.

Similarly, the overall unfavorable outcome and mortality observed in our study was $28.8 \%$ and $17.3 \%$ respectively. This is consistent with the study done by Egea-Guerrero et al. ${ }^{11}$ which showed unfavorable outcome and mortality as $25.5 \%$ and $16.2 \%$ respectively in patients with moderate to severe TBI. In a study done by Panczykowski et al. ${ }^{12}$ in a cohort of severe TBI patients, $73 \%$ had unfavorable outcome and $41 \%$ had mortality in 
6 months. Another study by Han et al. ${ }^{16}$ on similar patient population showed an unfavorable outcome of $71.0 \%$ and mortality of $47.7 \%$. However, in the study by Olivecrona et $\mathrm{al}^{13}$, the unfavorable outcome and mortality were much lower ( $45.8 \%$ and $14.6 \%$ respectively) even in patients with severe TBI. The inconsistency among various studies could be due to heterogeneous patient population. Our study is directly comparable to the study by Egea-Guerrero et $\mathrm{al}^{11}$ in a cohort of Spanish population.

The ROC curves were used to determine the discrimination ability of the score. The overall predictive performances of IMPACT scores showed significant correlation with mortality and unfavorable outcomes at 6 months in patients with moderate and severe traumatic brain injury. This corroborates well the results from Lingsma et $\mathrm{al}^{14}$, Raj et $\mathrm{al}^{17}$ and Egea-Guerrero et al. ${ }^{11}$ The comparison between previously published similar studies and our study is shown in table 5.

As shown in table 5, among three models, the IMPACT lab has the greatest discrimination in predicting outcomes (between favorable and unfavorable outcomes as well as survival and mortality) in patients with moderate to severe TBI. However, in the study conducted by Panczykowski et al. ${ }^{12}$ in severe TBI patients, the extended model consistently provided greater predictive power than either the core or lab models. The superiority of the extended over the core model can be explained by the use of additional secondary insults (hypoxia, hypotension) and CT predictors (Marshall CT classification, tSAH, and $\mathrm{EDH})$. The lower performance of the lab model in the same study was reported to be due to consequence of the relatively narrow hemoglobin and glucose distributions within their sample.

Of all successful three models, it is the IMPACT lab model that has the greatest capacity to discriminate between favorable and unfavorable outcomes as well as survival and mortality in our study though it didn't reach to the point of statistical significance. The superiority of the IMPACT lab model is a consequence of the inclusion of more variables into the model as explained above.

The Hosmer Lemeshow calibration plot showed good model fit for IMPACT core, IMPACT extended and IMPACT lab scores in diagnosing mortality and unfavorable outcome in six months $(\mathrm{p}>0.05)$, similar to study by Egea-Guerrero et $\mathrm{al}^{11}$ and Lingsma et $\mathrm{al}^{14}$ However, only IMPACT lab showed good model fit in the study conducted by Raj et al. ${ }^{17}$

\section{Conclusion}

The IMPACT score is a good prognostic tool to predict 6-month outcomes in moderate to severe TBI based on characteristics at admission in Nepalese patient population. Among the three IMPACT models, IMPACT lab has the greatest discriminating ability. Further multicenter studies involving larger sample size will better clarify the predictive ability of the IMPACT score.

\section{Conflict of Interest: None Source(s) of support: None}

\section{Abbreviations}

$\begin{array}{ll}\text { APACHE - } & \text { Acute Physiological and Chronic Health } \\ & \text { Evaluation } \\ \text { AUC } & \text { - Area Under Curve } \\ \text { CI } & \text { - Confidence Interval } \\ \text { GCS } & \text { - Glasgow Coma Scale } \\ \text { GOS } & \text { - Glasgow Outcome Score } \\ \text { ICU } & \text { - Intensive Care Unit } \\ \text { IMPACT } & \text { - International Mission for Prognosis and } \\ & \text { Analysis of Clinical Trials in TBI } \\ \text { PVS } & \text { - Persistent vegetative state } \\ \text { ROC } & \text { - Receiver Operating Curve } \\ \text { SAH } & \text { - Subarachnoid hemorrhage } \\ \text { TBI } & \text { - Traumatic Brain Injury }\end{array}$

\section{References}

1. Rubiano AM, Carney N, Chesnut R, Puyana JC. Global neurotrauma research challenges and opportunities. Nature. 2015;527(7578):S193-7. https://doi.org/10.1038/nature16035

2. Sherman C. Stein, Patrick Georgoff, Sudha Meghan, Kasim Mizra, and Seema S. Sonnad.Journal of Neurotrauma.Jul 2010. https://doi.org/10.1089/ neu.2009.1206

3. Roozenbeek B1, Maas AI, Menon DK Changing patterns in the epidemiology of traumatic brain injury. Nat Rev Neurol. 2013;9(4):231-6. https://doi. org/10.1038/nrneurol.2013.22

4. Lingsma HF1, Roozenbeek B, Li B, Lu J, Weir J, Butcher I, Marmarou A, Murray GD, Maas AI, Steyerberg EW. Large between-center differences in outcome after moderate and severe traumatic brain injury in the international mission on prognosis and clinical trial design in traumatic brain injury (IMPACT) study. Neurosurgery 2011;68(3):601-7. https://doi.org/10.1227/NEU.0b013e318209333b

5. Khuri SF1, Daley J, Henderson WG. The comparative assessment and improvement of quality of surgical care in the Department of Veterans Affairs. Arch Surg. 2002 Jan;137(1):20-7. https://doi.org/10.1001/ archsurg.137.1.20

6. Knaus WA, Draper EA, Wagner DP, Zimmerman JE APACHE II: a severity of disease classification system. Crit Care Med. 1985;13(10):818-29. https:// doi.org/10.1097/00003246-198510000-00009 


\section{Jha et al}

7. Lingsma HF1, Roozenbeek B, Steyerberg EW, Murray GD, Maas AI. Early prognosis in traumatic brain injury: from prophecies to predictions. Lancet Neurol. 2010 May;9(5):543-54. https://doi. org/10.1016/s1474-4422(10)70065-x

8. ICD-10 Version:2016. https://icd.who.int/ browse10/2016/en - /S06.0

9. B. Green, Samuel. (1991). How Many Subjects Does It Take to Do a Regression Analysis?. Multivariate Behavioral Research - multivariate behav res. 26 https://doi.org/10.1207/s15327906mbr2603 7

10. Steyerberg EW, Mushkudiani N, Perel P, et al. Predicting outcome after traumatic brain injury: development and international validation of prognostic scores based on admission characteristics. PLoS Med. 2008;5(8):e165.https://doi.org/10.1371/journal. pmed.0050165

11. Egea-Guerrero JJ, Rodríguez-Rodríguez A, GordilloEscobar E, Fernández-Delgado E, MartínezRoldán Á, Roldán-Reina Á, et al. IMPACT Score for Traumatic Brain Injury: Validation of the Prognostic Tool in a Spanish Cohort. J Head Trauma Rehabil. 2018;33(1):46-52. https://doi.org/10.1097/ HTR.0000000000000292

12. Panczykowski DM, Puccio AM, Scruggs BJ, Bauer JS, Hricik AJ, Beers SR, et al. Prospective independent validation of IMPACT modeling as a prognostic tool in severe traumatic brain injury. J Neurotrauma. 2012;29(1):47-52. https://doi. org/10.1089/neu.2010.1482
13. Olivecrona M, Koskinen LO. The IMPACT prognosis calculator used in patients with severe traumatic brain injury treated with an ICP-targeted therapy. Acta Neurochir (Wien). 2012;154(9):1567-73. https://doi. org/10.1007/s00701-012-1351-z

14. Lingsma H, Andriessen TM, Haitsema I, Horn J, van der Naalt J, Franschman G, et al. Prognosis in moderate and severe traumatic brain injury: external validation of the IMPACT models and the role of extracranial injuries. J Trauma Acute Care Surg. 2013;74(2):63946. https://doi.org/10.1097/TA.0b013e31827d602e

15. Kamal VK, Agrawal D, Pandey RM. Epidemiology, clinical characteristics and outcomes of traumatic brain injury: Evidences from integrated level 1 trauma center in India. J Neurosci Rural Pract. 2016;7(4):51525. https://doi.org/10.4103/0976-3147.188637

16. Han J, King NK, Neilson SJ, Gandhi MP, Ng I. External validation of the CRASH and IMPACT prognostic models in severe traumatic brain injury. J Neurotrauma. 2014;31(13):1146-52. https://doi. org/10.1089/neu.2013.3003

17. Raj R, Siironen J, Kivisaari R, Hernesniemi J, Skrifvars MB. Predicting outcome after traumatic brain injury: development of prognostic scores based on the IMPACT and the APACHE II. J Neurotrauma. 2014;31(20):1721-32. https://doi.org/10.1089/ neu.2014.3361 